\title{
Pancreatic Cancer Stem Cells and Therapeutic Approaches
}

\author{
GULINNAZ ERCAN $^{1,2}$, AYFER KARLITEPE ${ }^{1}$ and BULENT OZPOLAT ${ }^{3,4}$ \\ ${ }^{1}$ Department of Medical Biochemistry, Ege University Medical School, Izmir, Turkey; \\ ${ }^{2}$ Department of Stem Cell, Institute of Health Sciences, Ege University, Izmir, Turkey; \\ ${ }^{3}$ Department of Experimental Therapeutics and ${ }^{4}$ Center for RNA Interference and Non-Coding RNA, \\ The University of Texas, MD Anderson Cancer Center, Houston, TX, U.S.A.
}

\begin{abstract}
Pancreatic ductal adenocarcinoma (PDAC) is considered one of the deadliest human cancers, with 1-5\% 5 -year survival rates ( 6-month median survival duration) despite therapy; thus, PDAC represents an unmet therapeutic challenge. PDAC is the major histological subtype, comprising $90 \%$ of all pancreatic cancers. It is a highly complex and aggressive malignancy, presenting with early local invasion and metastasis, and is resistant to most therapies, all of which are believed to contribute to its extremely poor prognosis. PDAC is characterized by molecular alterations, including mutations of K-RAS ( 90\% of cases), TP53, transforming growth factor- $\beta$, Hedgehog, WNT and NOTCH signaling pathways. Given that cancer stem cells have a crucial role not only in tumor initiation and progression, but also in drug resistance and relapse or recurrence of various cancer types, they may be excellent targets for effective novel therapeutic approaches. Here, we reviewed recent therapeutic strategies targeting pancreatic cancer stem cells using chemotherapeutics and targeted drugs, non-coding RNAs (i.e., siRNA and miRNAs), immunotherapy, and natural compounds.
\end{abstract}

\section{Pancreatic Cancer}

Pancreatic cancer $(\mathrm{PaCa})$ is currently the third most common cause of cancer-related death in the United States (1-4).

This article is freely accessible online.

Correspondence to: Bulent Ozpolat, MD, Ph.D., Department of Experimental Therapeutics, Unit 422, The University of Texas MD Anderson Cancer Center, 1515 Holcombe Boulevard, Houston, TX 77030, U.S.A. Tel: +1 7135630166, Fax: +1 7137920362, e-mail: bozpolat@mdanderson.org

Key Words: Pancreatic cancer, cancer stem cells, polyphenolic, microRNA, targeted therapy, immunotherapy, drug resistance, review.
Pancreatic ductal adenocarcinoma (PDAC) is a major histological subtype, comprising of $90 \%$ of all PaCas (1). Although both the exocrine and endocrine cells of the pancreas can form cancer, tumors of the endocrine pancreas are less common; they are known as islet cell tumors (such as insulinomas, glucagonomas, and somatostatinomas) and neuroendocrine tumors (such as gastrinomas). $\mathrm{PaCa}$ formed by exocrine cells is much more common; nearly all of these tumors are adenocarcinomas (2).

PDAC has an extremely poor prognosis, with 5-year survival rates of $1-5 \%$ ( $\sim 6$-month median survival duration) with currently available therapies (5). The majority of patients with PDAC (80-90\%) have local metastasis at the time of diagnosis. These patients cannot benefit from surgery and instead undergo standard-of-care medical treatment using chemotherapeutics, including gemcitabine, or a combination of 5-flurouracil (5-FU) plus leucovorin (6). The high mortality rate of PDAC is attributed to its aggressive nature, early local and advanced metastasis, its intrinsic resistance to chemotherapeutics, and absence of effective therapies. In addition, lack of early diagnostic tests prevents early therapeutic interventions, and is considered to be an important factor that contributes to the poor prognosis of PDAC (4).

\section{Biology and Genetics of PaCa}

Pancreatic intra-epithelial neoplasms (PanINs) are the most common precursors of PDAC; they develop in a background of pancreatic inflammation. $K-R A S$ is mutated in approximately $90 \%$ of all PDACs and is found in almost all PanINs (7). Although K-RAS mutation is necessary for carcinogenesis and subsequent PDAC tumor maintenance, it is not sufficient to drive PanINs to develop into PDAC (8). In addition to K-RAS, mutations in tumor suppressors, including cyclin-dependent kinase inhibitor $2 \mathrm{~A}(C D K N 2 A)$ (encoding p16 ${ }^{\text {INK4A }}$ protein), mothers against decapentaplegic homolog 
4 (SMAD4), and TP53, are required for malignant transformation (9). More than 60 molecular alterations related to apoptotic pathways and Hedgehog $(\mathrm{HH})$, transforming growth factor- $\beta$ (TGF- $\beta$ ), WNT, and $\mathrm{NOTCH}$ signaling pathways have been identified in $\operatorname{PDAC}(10,11)$.

PDAC is also characterized by an excessive desmoplastic response, with generation of dense fibrotic tissue, an altered extracellular matrix, and hypovascularity that may be caused by HHS signaling (12). Highly dense fibrotic tissue constitutes $90 \%$ of the tumor volume; it is considered a barrier to effective drug delivery and prevents the penetration of therapeutics into tumor tissues. The other characteristic feature of PDAC is that it is resistant to chemotherapyinduced apoptosis due to intrinsic and acquired resistance to such therapies, and the presence of $\mathrm{PaCa}$ cancer stem cells (CSCs) (13). Recent emerging data indicate that CSCs are an important factor that contributes to the complex biology, tumorigenesis, progression, and poor clinical outcome of PDAC (14).

\section{Normal and Cancer Stem Cells}

Normal adult stem cells are tissue-specific cells that exhibit unique biological properties, including the ability to self renew and differentiate into various mature cells of specific tissues. Functionally, these cells undergo an unlimited number of asymmetrical cell divisions, and with each division, they produce at least one daughter progenitor cell that maintains their indefinite self-renewing capacity (15). When adult stem cells divide asymmetrically, they can also produce cells that have limited division capacity, ultimately differentiating into mature cells (16). Since adult cells such as epithelial and blood cells undergo continuous cellular turnover, adult stem cells form a pool of long-lived cells that provide a continuous supply of differentiated cells for the homeostatic control of specific tissue compartments (17).

Small subpopulation of cancer cells, CSCs, contribute to tumor initiation, growth, and metastasis; therapy resistance; and cancer recurrence $(14,18)$. They were first identified in acute myelogenous leukemia and subsequently in many solid cancer types, including $\mathrm{PaCa}$ (19). CSCs share core regulatory pathways with normal stem cells but have diversely distinct reprogrammed pathways. Like normal pluripotent stem cells, CSCs have both self-renewal and multilineage differentiation capacities (20). While normal pluripotent stem cells have tightly controlled self-renewal and committed lineage differentiation capacities, which prevent tumor development, CSCs have the capability to differentiate into multiple cell types, leading to tumor initiation and progression (21). CSCs can give rise to both more CSCs and progeny that ultimately differentiate into the different cell types in a tumor by dividing indefinitely. CSCs also give rise to tumors that phenotypically resemble their tissue of origin, either in their morphological characteristics or in their expression of tissue-specific genes (17). CSCs have quiescent potential in a dormant state and may be involved in both resistance to apoptosis and induction of angiogenesis. Thus, CSCs are not only considered tumorinitiating cells but also as cells that promote tumor development and therapy resistance, leading to disease progression and relapse $(14,18,19,22)$.

According to the CSC hypothesis, cancer-initiating cells are transformed tissue stem cells that are normally found in low numbers among the heterogeneous cells that comprise the malignant tumor mass; they retain the essential characteristic feature of self-protection through the activity of multiple drug resistance (MDR) transporters (23). Understanding the central role of MDR transporters in the protection and self-renewal of normal stem cells and CSCs may lead to the characterization of their differences, which could be used to develop therapeutic approaches that target CSCs. Strategies that only target cancer cells would not be sufficient to eliminate cancer or control the growth and progression of the disease (24).

In summary, tumor initiation, propagation, metastasis, and relapse are caused by a tiny subpopulation of cells called CSCs that are localized among cancer cells and have stem cell-like properties, with clonal long-term repopulation and self-renewal capacities. Due to their hierarchical organization, CSCs and non-CSC tumor cells share the same mutational and genetic background; however, CSCs are exclusively tumorigenic and therapy resistant (25). Thus, while developing therapeutic agents that are aimed to target and eliminate CSCs successfully, one should also consider the heterogeneity of CSCs (26). CSCs carry more differentiated cell features and characteristics among different cancer subtypes even in the same tumor and at different stages of progression. Thus, while CSCs undergo a differentiation process and give rise to tumor cells, there may be different markers at different stages of the cancer.

\section{PaCa Stem Cells}

Several common stem cell markers have been identified as CSC-specific markers in CSC subpopulations isolated from a wide variety of human cancer types and cell lines. These include octamer-binding transcription factor 4 (OCT4), sex determining region Y-box 2 (SOX2), homeobox protein (NANOG), tyrosine-protein kinase Kit (C-KIT), ATPbinding cassette sub-family $\mathrm{G}$ member 2 (ABCG2), cluster of differentiaition (CD) CD34, CD44, CD123, CD133, CD44V6, tyrosine-protein kinase Met (C-MET), tetraspanin8 (TSPAN8), integrin (A6B4), C-X-C chemokine receptor type 4 (CXCR4), claudin7, epithelial-specific antigen (ESA), and aldehyde dehydrogenase 1 (ALDH1) (18,19,22). Classically, CSCs are first isolated using techniques such as 
flow cytometry or magnetic bead sorting and then implanted in immunocompromised mice to determine their efficiency in tumor initiation and progression in vivo (18).

Although many markers have been identified for pancreatic CSCs, which represent fewer than $1 \%$ of all $\mathrm{PaCa}$ cells, a universal marker is still lacking. Markers that have been used in identifying neoplastic and non-neoplastic stem cells include CD44, CD24, CD133, ESA, ALDH1, and Hoechst dye exclusion (side population) (18). CD133, $\mathrm{ALDH} 1$, and the triplet combination of $\mathrm{CD} 24^{+} \mathrm{CD} 44^{+} \mathrm{ESA}^{+}$ are the best established PaCa CSC markers $(18,19,22)$. $\mathrm{CD} 44^{+} / \mathrm{CD} 24^{+} / \mathrm{ESA}^{+}$cells were found to be much more tumorigenic than were marker-negative $\mathrm{PaCa}$ cells and possessed the capacity to self-renew and differentiate into different progeny cancer cell types. When injected into nonobese diabetic (NOD)/severe combined immunodeficiency (SCID) mice, these CSCs self renewed and produced differentiated progeny. They had a 100-fold increased tumorigenic potential and maintained their surface marker phenotype after repeated passages as xenografts. In concordance with these findings, clinical data suggest that CD44 positivity is a poor prognostic indicator in patients with $\mathrm{PaCa}$ (17).

A pancreatic CSC population with CD133 expression exhibited increased tumorigenicity, a metastatic phenotype and more resistance to chemotherapy than did CD133- cells. During serial passages, $\mathrm{CD} 133^{+}$cells retained their ability to self-renew and generate differentiated non-tumorigenic descendants to reconstruct hierarchically organized tumors in an orthotopic mouse model. (27) In PaCa, a $\mathrm{CD}_{4} 4^{+} / \mathrm{CD} 133^{+}$cell population has also been demonstrated in both tumor specimens and $\mathrm{PaCa}$ cell lines. Meanwhile, $\mathrm{CD}_{4} 4^{+} / \mathrm{CD} 133^{+} \mathrm{MiaPaCa} 2$ cells, which express high levels of NOTCH and BCL2, were found to have a strong capacity to form tumorspheres in vitro and initiated tumors in a mouse xenograft model in vivo (28). CD $44^{+} / \mathrm{CD} 133^{+}$cells isolated from the PANC-1 cell line were also capable of forming tumorspheres in vitro, exhibited tumor-initiating potential in vivo, and profoundly responded to WNT pathway inhibition (22). Moreover, high expression levels of both CD44 and CD133 were also found to be associated with a poor prognosis in patients with $\mathrm{PaCa}(22)$.

$\mathrm{CD} 133^{+}$(cytokeratin $^{-}$) cells from human $\mathrm{PaCa}$ tissues displayed high tumorigenic potential (14). In a series of experiments, $\mathrm{CD} 44^{+} \mathrm{CD} 24^{+} \mathrm{ESA}^{+}$cells (comprising 0.2-0.8\% of the total cell population), identified by fluorescenceactivated cell sorting from primary human cancer tissues, were implanted in immune-compromised mice. A small volume of tumor cells was consistently observed (18). When engrafted into nude mice, an even smaller number of $\mathrm{CD} 133^{+}$cells (fewer than 500) routinely led to the formation of tumors; although these cells were highly tumorigenic, $\mathrm{CD} 133^{-}$cells were not able to induce tumor formation (18).
In addition to cell surface markers, the cellular molecule ALDH1, which catalyzes the oxidation of intracellular aldehydes and converts retinol to retinoic acid, was also implicated as a stem cell marker in $\mathrm{PaCa}$ due to its role in the early differentiation of stem cells $(18,22)$. ALDH1 ${ }^{+}$cells, which have a higher clonogenic capacity than do ALDH1 ${ }^{-}$ cells, were shown to be highly tumorigenic, able to initiate tumor development at low cell numbers, and undergo epithelial-mesenchymal transition (EMT) (22). Recently, $\mathrm{CD} 133^{+} / \mathrm{CXCR}^{+}$cells were found to exert a more invasive and metastatic phenotype $(15,22)$. $\mathrm{CD} 133^{+} / \mathrm{CXCR} 4^{+} \mathrm{CSCs}$ were detected in the invasive margin of pancreatic tumors, and removal of this subpopulation was shown to prevent tumor metastasis $(14,22)$. Moreover, the ligand of CXCR4, stromal cell-derived factor-1, was shown to enhance the in vitro chemotactic migration of $\mathrm{CD} 133^{+} / \mathrm{CXCR}^{+} \mathrm{PaCa}$ cells, while this migration was blocked by CXCR4 blocking/inhibiting antibodies (17). In addition, eliminating $\mathrm{CD} 133^{+} / \mathrm{CXCR}^{+}$cells by AMD- 3100 , which targets CXCR4, prevented the development of liver metastases in mice without affecting tumor-initiating ability (17). Since CD133 ${ }^{+} \mathrm{PaCa}$ cells represent distinct CSC subpopulations, all these markers $\left(\mathrm{CD} 24^{+} / \mathrm{CD} 44^{+} / \mathrm{ESA}^{+} / \mathrm{CD} 133^{+} / \mathrm{CXCR}^{+}\right.$, or even more markers, such as ALDH1) may be required for CSC enrichment $(4,19,22)$.

\section{Signaling Pathways Important for Pancreatic CSCs}

Signaling pathways have been implicated in $\mathrm{PaCa}$ tumorigenesis, prognosis, and resistance to therapy; thus, the identification of these pathways is considered a promising therapeutic strategy for the development of molecularly targeted therapies (18). CSCs are likely regulated by developmental pathways similar to those that regulate normal stem cells, including NOTCH, HH, WNT, polycomb complex protein (BMI1), and phosphatase and tensin homolog (PTEN) (17-19). Understanding the role of these key signaling pathways in CSC maintenance may lead to promising therapeutic targets in the treatment of $\mathrm{PaCa}$ and other types of cancer (22).

NOTCH signaling pathway. The NOTCH signaling pathway is considered a potential contributor to CSC maintenance and plays an important role in regulating the balance between self-renewal and differentiation during normal pancreatic tissue development $(19,22)$. Several studies have shown that pancreatic CSCs express high levels of NOTCH1 and NOTCH2 (22). NOTCH signaling is inhibited by the $\gamma$-secretase inhibitor $(\gamma$-SI), which leads to the depletion of pancreatic CSCs and impaired function (22). Up-regulation of several NOTCH pathway components in pancreatic CSCs compared to $\mathrm{PaCa}$ cells has been shown, and the inhibition of Hes family BHLH transcription factor 1 (HES1) (a key 
NOTCH target gene) by a $\gamma$-SI or small interfering RNA (siRNA) reduces pancreatic CSC self-renewal and tumorigenicity (22). Interestingly, although the $\mathrm{NOTCH}$ pathway has been shown to regulate the $\mathrm{HH}$ pathway by repressing $\gamma$-SI by HES1, no significant changes were observed in $\mathrm{HH}$ signaling components when $\mathrm{NOTCH}$ signaling was inhibited (29).

NOTCH signaling is also known to contribute to the regulation of EMT. Acquisition of the EMT phenotype in gemcitabine-resistant $\mathrm{PaCa}$ cells was found to be consistent with the up-regulation of NOTCH2, NOTCH4, and CD339 (JAGGED-1). Inhibition of NOTCH signaling using siRNA partially reversed the EMT phenotype. Collectively, these findings indicate that the NOTCH pathway is involved in the self-renewal of pancreatic CSCs and the EMT process (22). Therefore, the NOTCH signaling pathway represents a promising therapeutic target for targeting pancreatic CSCs and metastasis.

Hedgehog signaling. The HH pathway is an evolutionarilyconserved pathway essential for self-renewal of CSCs. It isrequired for normal stem and progenitor functionsas well as pancreatic morphogenesis and cellular differentiation; thus, dysregulation of $\mathrm{HH}$ signaling is considered one of the key events in $\mathrm{PaCa}$ pathogenesis (30). Transgenic mice that overexpressed Sonic HH (SHH), a ligand of HH signaling, in the pancreatic endoderm developed PanIN-like lesions that contained $K$-RAS mutations and overexpressed human epidermal growth factor receptor 2 (HER2/neu), revealing that the $\mathrm{HH}$ signaling pathway plays an early role in pancreatic tumorigenesis. Recent evidence also demonstrated that $\mathrm{SHH}$ and the other $\mathrm{HH}$ signaling components are highly expressed in pancreatic CSCs, but not in normal pancreatic stem cells or pancreatic ductal epithelial cells (22). The natural compounds sulforaphane, epigallocatechin-3 gallate (EGCG), and quercetin have been reported to impede the self-renewal capacity of pancreatic CSCs by attenuating the $\mathrm{HH}$ signaling pathway (31), indicating that $\mathrm{HH}$ signaling plays an important role in pancreatic CSCs.

$W N T / \beta$-catenin pathway. Activation of the $\mathrm{WNT} / \beta$-catenin pathway has been shown to be involved in $\mathrm{PaCa}$ development and progression (32). Although aberrant cytoplasmic and nuclear expression of $\beta$-catenin is frequently found in $\mathrm{PaCa}$ and PanIN tissue samples, it is not found in normal pancreatic tissues. High transcriptional activity of $\mathrm{WNT} / \beta$-catenin in $\mathrm{PaCa}$ is associated with poor diseasespecific patient survival, indicating the clinical significance of this pathway (22). Activation of the $\mathrm{WNT} / \beta$-catenin signaling pathway in CSCs leads to resistance to conventional therapies. Increased activation of $\mathrm{WNT} / \beta$ catenin signaling results in an enhanced stem cell-like phenotype of $\mathrm{PaCa}$ (33).
Other pathways important to pancreatic CSCs. In addition to the above-mentioned embryonic signaling pathways, other signaling pathways, such as autophagy, forkhead box protein M1 (FOXM1) signaling, interleukin 8 (IL8/CXCR1), mechanistic target of rapamycin (mTOR), and NODAL/ ACTIVIN signaling pathways, and the K-RAS/c-Jun-NH2kinase (JNK) axis have also been shown to be involved in the regulation of $\mathrm{PaCa}$ CSC activity (22); however, the significance of these signaling pathways has not been clarified.

\section{Major Obstacles and Potential Strategies for Targeting Pancreatic CSCs}

CSC drug resistance. CSCs are thought to be intrinsically resistant to chemotherapeutic agents and radiation therapy, although the mechanism of this resistance is not entirely clear (18). Cancer cells that acquire resistance to chemotherapeutic agents may display cross-resistance to a broad spectrum of structurally-unrelated drugs due to MDR (34). The most common drug resistance mechanisms include metabolic inactivation, efflux of the drug from the cells, and mutation or overexpression of the drug target (35). Numerous studies have revealed that the MDR phenotype in tumors is associated with the overexpression of certain drug efflux transporter proteins, the ATP-binding cassette (ABC) transporters (36). These proteins bind ATP and use the energy to transport various molecules across cell membranes, reducing the effects of the drugs in cancer cells. This is also one of the principal mechanisms for protecting stem cells. Therefore, there is renewed attention being paid to the role of $\mathrm{ABC}$ transporters in CSC biology (35).

Transporters such as P-glycoprotein (ABCB1), breast cancer resistance protein $(\mathrm{ABCG} 2)$, and the $\mathrm{MDR}$-associated protein (ABCC1) have been identified in CSCs (37) and are considered to be important targets for overcoming drug resistance. Among these, P-gp, an ABC transporter with broad substrate specificity, is considered to be the most significant factor in the failure of treatment for leukemia and many solid tumors. ABCG2 seems to play an important role in CSC resistance to anticancer drugs in clinical applications (38). These mechanisms have been shown to be responsible for resistance in brain, colon, and pancreatic cancer (18). In drug-resistant cancer cells, increased CD133 expression and the regulation of protein kinase $\mathrm{B}$ (AKT) signaling were shown to be associated with high ABCG2 levels (36). Improved DNA repair, a low mitotic rate, increased ALDH oxidation of aldehydes or detoxification, and resistance to apoptosis are also thought to be involved in mediating chemotherapeutic resistance, while increased repair capacity of the DNA damage checkpoint is involved in radiotherapy resistance in CSCs. (39)

Quiescence of CSCs. CSCs are presumably arrested at a $\mathrm{G}_{0^{-}}$ like cell-cycle phase or checkpoint. Since the quiescent state 
of these CSCs may account for many treatment failures, the only effective way to treat cancer is to target CSCs by blocking their ability to self-renew and generate multilineage differentiation (40).

Stem-cell 'niche'. An in vivo or in vitro stem cell 'niche', a specific microenvironment for CSCs, has also been proposed to contribute to resistance via various mechanisms, including MDR and ABC transporters. EMT, inflammation, hypoxia, and angiogenesis further contribute to the regulation of CSCs. Thus, the CSC niche needs to be targeted since this specific microenvironment plays important roles in tumor growth, metastasis, and response to standard therapies.

Furthermore, stemness markers have been shown to be linked to chemoresistance in $\mathrm{PaCa}$. $\mathrm{CD} 133^{+}$cells isolated from patients with $\mathrm{PaCa}$ have been shown to be significantly more resistant to gemcitabine than are CD133- cells (41). Prolonged gemcitabine exposure leads to a decrease in tumor size in xenograft models while causing an increase in the $\mathrm{CD}_{133^{+}}$cell fraction in a dose-dependent manner. Similar results have been observed for CSCs after 5-FU exposure. On the other hand, stem cell markers such as $\mathrm{CD} 44^{+} \mathrm{CD} 24^{+} \mathrm{ESA}^{+}$have also been found to be expressed in cells that are resistant to both gemcitabine therapy and radiotherapy. Interestingly, gemcitabine treatment eliminates only the bulk of tumor cells while leaving both the CD44 ${ }^{+}$ enriched cell population and a small subset of $\mathrm{CD} 44^{+} \mathrm{CD} 24^{+} \mathrm{ESA}^{+}$cells that are capable of proliferating and regenerating tumor. In an in vitro study, it was shown that high-dose gemcitabine eliminated most $\mathrm{PaCa}$ cells while failing to eliminate $\mathrm{CD}_{4} 4^{+}$and $\mathrm{CD} 44^{+} / \mathrm{CD} 24^{+} \mathrm{CSCs}$; proliferating $\mathrm{CD}_{4} 4^{+} \mathrm{CSC}$ generated resistant $\mathrm{PaCa}$ cells (42). Clinical data confirmed this finding, showing that patients with $\mathrm{PaCa}$ with a poor prognosis have $\mathrm{CD} 44$ positivity (43). These findings suggest that $\mathrm{PaCa}$ $\mathrm{CD} 44^{+} / \mathrm{CD} 24^{+} \mathrm{CSC}$ are responsible for gemcitabine resistance and, thus, poor prognosis. A study also demonstrated that gemcitabine-resistant human $\mathrm{PaCa}$ tissues, which are rich in $\mathrm{PaCa} \mathrm{CD}_{133}{ }^{+} \mathrm{CSCs}$, are highly tumorigenic, as they are capable both of forming colonies and resisting conventional chemotherapy (44). A cell adhesion molecule called CXCR4, the receptor for CXCL12 (stromal cell-derived factor-1, SDF1) that was found only at the invasive margin of the tumor, was shown to be responsible for the difference in response to therapies, leading to metastasis in a murine model (18).

\section{Potential Therapies Targeting CSCs}

Reactive oxygen species (ROS) inhibitors. While investigating the molecular mechanisms underlying chemoresistance to 5-FU and gemcitabine therapies in $\mathrm{PaCa}$, Suziki et al. discovered that the JNK pathway, through suppression of intracellular ROS levels, plays a critical role in the development of resistance in pancreatic CSCs (45). Targeting the JNK-ROS axis, in combination with 5FU or gemcitabine-based regimens, may be a promising approach to eliminating pancreatic CSCs for the more successful treatment of $\mathrm{PaCa}$.

Acetyl salicylic acid. Aspirin was shown to inhibit cell signaling for self-renewal capacity, tumor growth, and invasion by inhibiting markers of inflammation, and it sensitized CSCs to gemcitabine-mediated cytotoxicity both in vitro and in vivo. It has been demonstrated that aspirin can inhibit the characteristic features of CSCs through inhibition of inflammatory activity, self-renewal potential, stem cell marker expression, tumor growth, metastasis and stromal reaction, and can enhance the efficacy of gemcitabine (46).

mTOR inhibitors. Since the mTOR signaling pathway is aberrantly activated in various human malignancies and plays a crucial role in CSCs, mTOR inhibitors have been proposed and used as a novel strategy for eliminating CSCs. Various mTOR inhibitors, including rapamycin, everolimus, temsirolimus, and ridaforolimus, have been used to target CSCs (47). Gemcitabine treatment of PaCa cell lines or cells derived from primary human $\mathrm{PaCa}$ tumors leads to enrichment of the $\mathrm{CD}_{133^{+}} \mathrm{CSC}$ population. Rapamycin reduces the viability of $\mathrm{CD}_{133^{+}} \mathrm{PaCa}$ cells and sphere formation, which is indicative of the self-renewal of stemlike cells, indicating that the mTOR pathway maintains cancer stem-like cells $(48,49)$. Combining gemcitabine with rapamycin has been found to highly suppress CSC survival, suggesting that mTOR inhibitors may be used especially in combination with standard therepies to target CSCs $(48,49)$.

Metformin. Metformin is an anti-diabetic drug that has been implicated in targeting CSCs, including pancreatic CSCs; it reduces the expression of self-renewal-associated genes such as NANOG, OCT4, and SOX2 in cells that are positive for CD133, CD44, CXCR4, and stage-specific embryonic antigen 1 (SSEA1). Metformin exerts its action by activating the liver kinase B1- AMP-activated protein kinase (LKB1AMPK) axis and thereby indirectly inhibiting the mechanistic target of rapamycin complex 1 (mTORC1) (52). Mohammed et al. investigated the effect of metformin on PanIN, and found that the incidence of PDAC was reduced by about $20 \%$ with metformin treatment; while tumor weight and tumor metastasis were also decreased in a dosedependent manner in mice (53).

The expression of CSC markers in pancreatic tissue were found to be significantly reduced; as indicated by lower levels of CD44-, CD133-, ALDH1- and epithelial cell adhesion molecule (EPCAM)-positive cells. These results suggest that the biological effects of metformin are mediated 
by a decreased number of CSCs, indicating that metformin has significant potential for targeting pancreatic CSCs (54).

Metformin was also found to increase ROS production in CSCs and reduce mitochondrial transmembrane potential by hampering the cells' self-renewal capacity; it significantly reduced the size and number of tumor spheres and delayed the formation of secondary and tertiary tumorspheres. In cancer cells, metformin reduces cell proliferation and protein synthesis (55).

Glucose transporter 1 (GLUT1) inhibitors. CSCs are dependent on glycolysis for their survival and growth; thus, glucose metabolism is even more active in CSCs. Such increase in glucose metabolism is now known to be a hallmark of cancer (54). GLUT1 is a facilitative glucose transporter that is essential for the maintenance of pancreatic CSCs, and a specific GLUT1 inhibitor, WZB117, was found to be capable of suppressing the self-renewal and tumorinitiating capacities of CSCs without compromising their proliferative potential in vitro via inhibition of GLUT1. The systemic administration of WZB117 also inhibited tumor initiation in vivo after CSC implantation without causing significant side-effects in host animals. Since these results indicate that GLUT1-dependent glucose metabolism has a crucial role not only in the growth and survival of CSCs but also in the maintenance of their stemness, GLUT1 may also be considered a promising target for CSC-directed cancer therapy (56).

Histone deacetylase (HDAC) inhibitors. HDAC inhibitors, including suberylanilidehydroxamic acid (SAHA), reactivate aberrantly silenced genes by restoring histone acetylation. SAHA has been shown to inhibit cell growth and induce apoptosis in many types of human cancer by activating caspase3, caspase-9, peroxisome proliferator-activated receptors (PPAR) cleavage, cytochrome $c$ release, and the up-regulation of FAS and FAS ligand expression. A combination of SAHA and the SMOOTHENED antagonist SANT1 was shown to suppress cell growth and induce apoptosis in gemcitabineresistant PaCa cell lines. Moreover, SAHA was shown to be capable of inhibiting cell growth and inducing apoptosis, differentiation, and cell cycle arrest by up-regulating $p 21$, CCAAT/enhancer binding protein alpha $(C / E B P a)$, retinoic acid receptor alpha $(R A R A)$, and E-cadherin while down-regulating cyclin B1, cyclin D1, and c-MYC, suggesting that it is a promising therapeutic agent for human pancreatic CSCs (54).

Salinomycin. Salinomycin is another drug that is used to target $\mathrm{CD} 133^{+}$pancreatic CSCs; it was shown to be effective at eradicating $\mathrm{PaCa}$ xenografts in mice when used in combination with gemcitabine (57). The mechanism of action by which salinomycin kills CSCs specifically is not well established but it is thought to function as a potassium ionophore. Salinomycin and its derivatives exert significant antiproliferative activity towards drug-resistant cancer cell lines. Salinomycin can induce apoptosis of human cancer cells and effectively eliminate CSCs and induce partial clinical regression of heavily pretreated and therapy-resistant cancer (58).

Sorafenib. Sorafenib is an Food and Drug Administration (FDA)-approved small inhibitor of several tyrosine protein kinases, such as vascular endothelial growth factor receptor, platelet-derived growth factor, and serine/threonine-protein kinase (RAF) family kinases. Sorafenib is used for the treatment of advanced kidney and liver cancer and has been shown to target pancreatic CSCs and induce apoptosis and decrease proliferation, spheroid formation, clonogenicity, ALDH1 activity, and angiogenesis. Its use leads to an increase in survival $(59,60)$. Sulforaphane, an isothiocyanate found in broccoli, was shown to eliminate pancreatic CSCs by down-regulating NF-kB activity without inducing toxic side-effects; this activity was enhanced when it was combined with sorafenib (61).

Irinotecan plus gemcitabine. Recently, Qin et al. developed an electrospun scaffold made of polycaprolactone and gelatin to facilitate the survival and tumorigenesis of $\mathrm{CD} 24^{+} \mathrm{CD} 44^{+}$ $\mathrm{CSC}$ in $\mathrm{PaCa}$ tumor murine models in vivo; they found increases in both tumor formation incidence and in vivo tumor growth and concluded that the homogeneous nature of $\mathrm{CD} 24{ }^{+} \mathrm{CD} 44^{+} \mathrm{CSCs}$ significantly reduced the biological variation of $\mathrm{PaCa}$ tumor masses harvested from patients. When they evaluated the therapeutic effect of irinotecan plus gemcitabine on murine models of pancreatic tumor in vivo, they discovered that it was a promising chemotherapy for $\mathrm{PaCa}$ because of its devastating influence on $\mathrm{CD} 24^{+} \mathrm{CD} 44^{+}$ pancreatic CSCs (62).

Carbon ion beam. Combined with gemcitabine, carbon ion beam therapy has a superior effect on pancreatic CSCs and tumor growth in vitro and in vivo at relatively low doses in comparison to carbon ion beam alone or conventional x-ray irradiation. Carbon ion beam combined with gemcitabine synergistically enhanced the death of pancreatic CSCs by inhibiting DNA repair, as well as by inducing irreparable complex DNA damage via increasing apoptosis and autophagy and inhibiting cell proliferation at relatively low doses compared to carbon ion beam alone. Taken together, these results demonstrate the benefits of carbon ion beams in combination with chemotherapy in targeting conventional radioresistant locally advanced $\mathrm{PaCa}$ (63).

Inhibitors of facilitates chromatin transcription (FACT). CBL0137 is a member of a new class of recently discovered candidate anticancer agents that target FACT (SSRP1 and 
SPT16 subunits), as monotherapy or in combination with gemcitabine. In patient-derived PDAC xenografts and PANC-1 orthotopic tumors, CBL0137 inhibited gemcitabineinduced CSC enrichment; this, together with the in vivo data, make CBL0137 a reasonable and promising adjuvant treatment for gemcitabine since CBL0137 kills the CSCs while gemcitabine eliminates the remaining bulk population. As a result, CBL0137 is effective at preventing cancer recurrence (64).

Insulin-like growth factor-1 receptor (IGF1R) and epidermal growth factor receptor (EGFR) inhibitors. The impact of the concurrent inhibition of IGF1R and EGFR (HER2) has been shown in PaCa cell lines and particularly in pancreatic CSCs. NVP-AEW541 and lapatinib in combination simultaneously inhibited IGFIR and ERBB receptors/HER2 and thus prevented the resistance observed at the molecular level with individual treatments. Interestingly, these inhibitors eliminated $\mathrm{PaCa}$ cells and overcame their resistance to conventional chemotherapy. Thus, the synergy observed with this combined treatment indicates that the appropriate combination of currently known anticancer agents is efficient at maximizing patient benefit (65).

Carboxypeptidase inhibitors. Latexin is the only known mammalian carboxypeptidase inhibitor; it is an antigen expressed in a subset of neurons in the rat cerebral cortex, as well as in various types of non-neural tissues, such as heart, prostate, ovary, kidney, pancreas and colon tissue. Latexin shares $30 \%$ sequence similarity with tazaroteneinduced gene 1, which is down-regulated or absent in many tumor subtypes. Xue et al. investigated the differential expression of latexin in both $\mathrm{CD} 133^{+} \mathrm{PaCa}$ stem-like cells and $\mathrm{CD} 133^{-} \mathrm{PaCa}$ cells. They tested the effect of exogenous latexin in inducing apoptosis and inhibiting proliferation in $\mathrm{CD} 33^{+} \mathrm{PaCa}$ stem-like cells and studied the underlying mechanisms. It was demonstrated that latexin induces apoptosis in and inhibits the proliferation of $\mathrm{CD}_{13}{ }^{+}$ pancreatic CSCs derived from MiaPaca- 2 by modulating the BCL2 family and c-MYC; thus, targeting latexin may be a new therapeutic strategy for $\mathrm{PaCa}(66)$.

\section{Role of MicroRNA (miRNA, miR) in Pancreatic CSCs}

MicroRNAs (miRNAs are endogenous non-coding short RNAs (length of 21-23 nucleotides) encoded by nuclear DNA that are involved in the posttranscriptional regulation of gene expression. By binding to specific sequences of messenger RNA (mRNA) complementarily, they lead to gene silencing via translational repression or target degradation. miRNAs play a crucial role in various developmental, metabolic, and cellular processes, such as apoptosis, cell proliferation and differentiation, by altering the expression of proto-oncogenes or tumor-suppressor genes and thus regulating their levels in various tumor tissues (67). Moreover, miRNAs have a crucial role in tumorigenesis: an important alteration is found in the expression of protooncogenes or tumor-suppressor genes in cancer, including $\mathrm{PaCa}$, which is associated with clinical prognosis, therapy resistance and tumor recurrence or relapse. By affecting signaling pathways and CSC signature genes, miRNAs are also able to regulate CSC characteristics (68). Indeed, several microRNAs have already been implicated in the regulation of normal stem cells and CSCs.

$m i R-1181$ was recently shown to inhibit stemness and tumorigenicity. miR-1181 expression suppressed the CSC phenotypes of $\mathrm{PaCa}$ by targeting SOX2 and signal transducer and activator of transcription 3 (STAT3) (69). SOX2 has an important function during embryonic development and is involved in the maintenance of CSC phenotypes by directly targeting the genes that control tumor survival, proliferation, stemness, and invasion. SOX2 is overexpressed in both poorly differentiated $\mathrm{PaCa}$ and highly invasive PaCa. STAT3 is frequently overexpressed in $\mathrm{PaCa}$ and plays an important role in its pathogenesis. Since miR-1181 was found to be down-regulated in $\mathrm{PaCa}$ cell lines and clinical patient tissues, its therapeutic delivery and expression in $\mathrm{PaCa}$ tumors may be an important strategy in targeting pancreatic CSCs and cancer cells (69). $m i R-21$ and $m i R-221$ are up-regulated in pancreatic CSCs and contribute to important biological functions in cancer progression by promoting cell proliferation and migration and chemotherapy resistance. Inhibition of $m i R-21$ and $m i R-221$ by targeting CSCs may be a therapeutic strategy for $\mathrm{PaCa}(70)$.

miR-17-92 cluster: Epigenetic mechanisms may also account for the strong phenotypical differences seen in CSCs. The miR-17-92 cluster is down-regulated in chemoresistant CSCs. NODAL/ACTIVIN/TGF $\beta 1$ signaling, which promotes chemoresistance in CSCs, is inhibited by the miR-17-92 cluster. Overexpression of miR-17-92 leads to the abrogation of CSC phenotypes and the eventual loss of the in vivo tumorigenicity of CSCs (71).

LIN28B is an RNA-binding protein that regulates cell growth and differentiation. A novel CSC subpopulation that overexpresses both CD44 and LIN28B at the cell surface is found in human primary $\mathrm{PaCa}$ tissues; this $\mathrm{CD} 44^{+} / \mathrm{LIN}^{28 \mathrm{~B}^{+}}$ pancreatic CSC subpopulation proliferates rapidly and exhibits MDR, highly invasive ability, and high adherin levels. Therefore, $\mathrm{CD} 44^{+} / \mathrm{LIN} 28 \mathrm{~B}^{+}$pancreatic CSCs may represent a powerful in vitro model, either to study cancer cell metastasis, invasion, and self-renewal or to assess the effectiveness of novel therapeutics for PDAC. $\mathrm{CD}_{4} 4^{+} / \mathrm{LIN}_{28 \mathrm{~B}^{+}}$pancreatic CSCs were more resistant to growth inhibition when cisplatin and gemcitabine hydrochloride were used as chemotherapeutic drugs and 
rapidly and easily formed tumors in vivo. siRNA interference in endogenous LIN28b gene expression in these $\mathrm{CD}_{4}{ }^{+} / \mathrm{LIN}_{2} 8 \mathrm{~B}^{+}$pancreatic CSCs not only reduced their proliferation but also inhibited the cell cycle due to the suppression of cyclin D1 expression after the stimulation of miRNA LET-7B expression (72).

$m i R-1246$ has been shown to induce chemoresistance and contributes to CSC stemness in PaCa cell lines. $m i R-1246$ targets and controls the function of the cyclin-G2 (CCNG2) tumor suppressor gene. Given that CCNG2 participates in inhibiting cancer proliferation, invasion, differentiation, and chemoresistance, which characterize CSCs, CCNG2 inhibition may be at least partially responsible for the maintenance of CSC-like spheroid cells. CCNG2 expression is negatively correlated with $m i R-1246$ expression, suggesting that the miR-1246-CCNG2 axis is critical for chemoresistance and can be used to control CSCs (73).

$m i R$-335: An miRNA array assay showed that miR-335 is linked to OCT4 expression in PaCa. When OCT4overexpressing cells were infected with LV-miR-335, migration and invasion decreased as did levels of the mesenchymal markers fibronectin, vimentin, $\alpha$-Smooth muscle actin, and snail family transcriptional repressor 1 , while those of the epithelial marker E-cadherin increased in $\mathrm{PaCa}$ cells, suggesting that $m i R-335$ can inhibit metastasis and EMT in $\mathrm{PaCa}$ cells. Systemically delivered $m i R-335$ was found to inhibit PaCa metastasis and extend animal survival (74).

\section{Immunotherapy for Pancreatic CSCs}

Immunotherapy is a promising strategy that offers a complementary method for successfully treating cancer. The current strategies consist of cancer vaccines as active immunization, monoclonal antibodies as passive immunization, and cellular therapies that often include lymphocytes and dendritic cells. Cancer vaccines may be effective at preventing cancer by attacking various tumor cells, inducing an immune response (75).

Interferon- $\gamma$ (IFN $\gamma$ ) belongs to a group of type-I interferons and exerts its cellular activity by binding to a specific membrane receptor on the surface of many types of cells, including malignant cells. IFN $\gamma$ shows its therapeutic effects by improving the differentiation, maturation, and function of dendritic cells, enhancing the survival of T-cells through the expression of anti-apoptotic genes, generating $\mathrm{CD}^{+}$memory cells, enhancing macrophage activities, and activating natural killer cells and has already been approved for clinical cancer therapies of melanoma and renal cell carcinoma. Interestingly, IFN $\gamma$ up-regulates the expression of the CSC markers CD24, CD44, and CD133 in in vitro and in vivo models of PDAC in correlation with the original level of surface marker expression. While IFN $\gamma$ has a certain cytotoxic effect on PDAC cells and reduces their numbers, it conversely enhances the enrichment of PDAC CSCs. Given that IFN $\gamma$ 's effects on the migration and invasion of PDAC cells are associated with the level of CSC marker expression in vivo, IFN may promote metastasis in the early stage of tumor growth while inhibiting tumor growth; thus, it needs to be carefully considered as a therapeutic option in PDAC (76).

EpCAM is a marker of poor prognosis and is overexpressed in many types of human cancer, including $\mathrm{PaCa}$. Therapies targeting EpCAM can inhibit various types of cancer. Recently, catumaxomab, a bi-specific antibody that binds to EpCAM on tumor cells and CD3 on T-cells for activation, was approved by the FDA to treat malignant ascites. The combination of catumaxomab and activated Tcells has been shown to eradicate pancreatic CSCs. Pretreatment with catumaxomab, followed by the addition of IL2/OKT3-activated autologous T-cells, eliminated CSCs during a short incubation period. Moreover, the CSCs, which became more aggressive when MU-PK1 cells were cultured under hypoxic conditions were successfully lysed by the combination of cytokine-activated killer T-cells with catumaxomab. In conclusion, catumaxomab combined with activated T-cells may be a potent therapeutic modality for eradicating chemoresistant pancreatic CSCs (77).

CSC vaccines: Pancreatic CSCs that were isolated from tumor specimens and cultured were used to produce a vaccine that was evaluated for its safety and efficacy in low, medium-, and high-dose groups (78). When comparison of pre- and post-vaccination immunity was made; it was found to be significantly strengthened in the high-dose group with no side-effects, suggesting that the pancreatic CSC vaccine is safe and effective. However, from the viewpoint of a longterm curative effect, the benefit of the CSC vaccine on progression-free survival and overall survival requires further refinement (78).

Dendritic cells (DCs) are potent antigen-presenting cells that play a crucial role in inducing primary immune responses against tumor-associated antigens. To generate anti-tumor immune responses, DCs have been charged with pancreatic CSC antigens (79). After being co-cultured with lymphocytes at different ratios, the lysate-exposed DCs effectively promoted lymphocyte proliferation and induced the secretion of high levels of INF $\gamma$ and IL2, which are strong antitumor cytokines. The DCs had significant cytotoxic effects on Panc-1 CSCs and parental Panc-1 cells.

\section{Natural Dietary Compounds Against Pancreatic CSCs}

Recently, dietary compounds have gained substantial attention for their potential therapeutic applications in cancer, leading to the novel term 'nutraceutical', generated by combining the words nutrition and pharmaceutical. Indeed, 
nutraceuticals, particularly soy isoflavone genistein, curcumin, resveratrol, quercetin, EGCG, and lycopene, can inhibit not only cancer cells but also CSCs in $\mathrm{PaCa}$ and other cancer types (80).

Genistein. Soybeans are rich in natural phytoestrogenic isoflavones, particularly genistein, daidzein, and glycitein . Genistein (4,5,7-trihydroxyisoflavone) has multiple biological effects in various human cancer types, with low toxicity towards normal cells (81). Genistein inhibits cell growth, migration, invasion, angiogenesis, and metastasis through the regulation of multiple cellular signaling pathways, including the inhibition of NF-kB, WNT, $\mathrm{NOTCH} 1$, and $\mathrm{HH}$ pathways, and by acting as a protein tyrosine kinase inhibitor (mostly of EGFR) in human cancer (82). Genistein inhibits cell growth and pancreatosphere formation and reduces the expression of CSC surface markers, mainly by down-regulating the NOTCH pathway. Moreover, it has been shown to induce apoptosis in $\mathrm{PaCa}$ cell lines by inhibiting NF- and NOTCH1 signaling. Genistein attenuates $\beta$-catenin-mediated expression of WNT downstream target genes in mammary epithelial cells by upregulating E-cadherin. It modulates the expression of genes involved in cellular functions, such as proliferation, apoptosis, and angiogenesis, particularly by inhibiting or down-regulating the AKT and NF-kB pathways (83). Genistein is also capable of potentiating the antitumor effects of chemotherapeutic agents (e.g., gemcitabine, cisplatin, andoxaliplatin) by modulating the apoptotic pathways (84). In orthotopic animal models, genistein combined with gemcitabine synergistically increased the growth inhibition of PaCa cells through NF-kB inhibition. It also significantly improved the outcome of patients with advanced $\mathrm{PaCa}$ treated with erlotinib, an inhibitor of EGFR signaling, and gemcitabine (84). Genistein can overcome cancer drug resistance and inhibit cancer relapse and recurrence (85). Overall data suggest that genistein potentiates anticancer effects by promoting both apoptotic and autophagic cell death and inhibiting multiple signaling pathways in $\mathrm{PaCa}$ and PaCa-derived CSCs (86).

Curcumin. Curcumin (diferuloylmethane) is present in the rhizome of turmeric (Curcuma longa) $(87,88)$. Curcumin exerts anticarcinogenic, antioxidant, antimicrobial, and antiinflammatory activities, has hepatoprotective and renoprotective properties, and has hypoglycemic effects. In preclinical studies using both in vitro and in vivo models, curcumin exhibited antiproliferative, antioxidant, antiinflammatory, and pro-apoptotic effects, leading to antitumor effects in various cancer types, including thyroid, lung, and breast cancer, hepatocellular carcinoma, and $\mathrm{PaCa}(89,88)$. Moreover, curcumin inhibited the growth, migration, angiogenesis, invasion, and metastasis of $\mathrm{PaCa}$ cells by suppressing multiple cellular signaling pathways, such as AKT, NF-kB, and NOTCH (87). It was also found to inhibit the activity of distinct signaling pathways, including mTOR, HH, EGFR, STAT3, and multidrug transporters such as MDRassociated protein 5 (ABCC5). It modulates the expression levels of different oncogenic and tumor supressor microRNAs (90). In addition, curcumin has synergistic effects with gemcitabine (91). By modulating the activation of various transcription factors, curcumin regulates the expression of inflammatory enzymes, cytokines, adhesion molecules, and cell survival proteins (92). Curcumin also down-regulates cyclin D1, cyclin E, and mouse double minute 2 homolog (MDM2) and up-regulates $p 21, p 27$, and p53 (93).

Recent preclinical and clinical studies have demonstrated the antitumor and anti-angiogenic properties of curcumin (94). Curcumin enhanced the effects of 5-FU and oxaliplatin in mediating the growth inhibition of colon cancer cells by modulating EGFR and IGFR $(95,96)$. The efficacy of curcumin in the treatment of $\mathrm{PaCa}$ was also assessed: both phase I and II clinical trials have yielded promising results on the use of curcumin in PaCa therapy. More importantly, curcumin was safe and non-toxic, even at high doses, in clinical trials and preclinical models $(97,98)$. Overall, data from pre-clinical and clinical studies suggest that curcumin is a safe $\mathrm{PaCa}$ therapeutic agent due to its broad effects on $\mathrm{PaCa}$ cells, the tumor microenvironment, and pancreatic CSCs.

Resveratrol. Resveratrol (trans-3,5,4'-tri-hydroxystilbene) is a natural polyphenol that is mainly found in the skins of red grapes, red wine, berries, and peanuts (99-101). Resveratrol has received a great deal of attention as a cancerchemopreventive agent. It has been demonstrated to have an antitumorigenic capacity by inducing growth inhibition, cellcycle arrest, apoptosis, and changes in biomarker expression in more than 30 types of tumor cells, including those originating from the pancreas (100). Resveratrol inhibits cell growth and prevents metastasis in $\mathrm{PaCa}$ through the induction of mitochondrial dysfunction, cytochrome $c$ release, caspase activation, and apoptosis (100). Resveratrol can suppress $\mathrm{PaCa}$ cell migration, invasion, and the progression of EMT through inhibition of the $\mathrm{PI} 3 \mathrm{~K} / \mathrm{AKT} / \mathrm{NF}-\mathrm{KB}$ signaling pathway. It has been found to suppress the growth and self-renewal capacity of pancreatic CSCs derived from $k$-ras transgenic mice and human primary tumors. Therefore, the potential effect of resveratrol against CSCs needs to be further investigated, especially its effects on signaling pathways (102). Resveratrol has been shown to directly inhibit the proliferation and viability of human $\mathrm{PaCa}$ cells in vitro in a dose- and time-dependent manner $(100,101)$. Resveratrol treatment may thus be a novel therapeutic option for $\mathrm{PaCa}$ by inhibiting the $\mathrm{HH}$ signaling pathway (101). 
Quercetin. Flavonoids are one of the most actively studied classes of molecules for their potential to prevent cancer. Quercetin, 3,3',4',5,7-pentahydroxylflavone, is a natural dietary polyphenol and flavonol-type flavonoid that is ubiquitously present in fruits and vegetables, such as broccoli, onions, tea, apples, and berries (103-105). It has been well-documented that quercetin is a potential anticancer agent in in vitro and in vivo models. Quercetin exerts its anticancer effect through the inhibition of several intracellular pathways in cancer cells, including PI3K/Akt/mTOR, glycogen synthase kinase 3 (GSK3 $\beta$ ), NF$\mathrm{kB}$, and heat-shock protein $70(105,106)$. It elicits antitumor effects by acting as an antioxidant; modulating signaling pathways; inducing apoptosis, autophagy, and cell cycle arrest; blocking cell migration protein kinase $\mathrm{C}$ inhibitory activity; and inhibiting the fatty acid synthesis required for de novo membrane synthesis (106-108). Quercetin also suppressed local and distant tumor growth and prolonged survival in murine PaCa models. Quercetin itself showed growth-inhibitory activity in both drug-sensitive and MDR1 cells. In addition, at a non-cytotoxic concentration, it enhanced the effect of chemotherapeutic drugs in MDR cells. Quercetin has also been shown to act as a chemosensitizer for ABC pump-proteins in MDR tumor cell lines. Furthermore, it interacts directly with transporter proteins to inhibit drug efflux, mediated by either MDR1, MRP1, or BCRP (109, 110). Quercetin also suppressed local and distant tumor growth and prolonged survival in murine $\mathrm{PaCa}$ models (104). Quercetin targets pancreatic CSCs by inhibiting the $\beta$-catenin signaling pathway (106). It reduced the self-renewal properties of CSCs and ALDH activity in $\mathrm{PaCa}$ (103, 107). More importantly, quercetin showed synergistic effects in eliminating pancreatic CSCs in vitro and in vivo when combined with sulforaphane (107). Quercetin may be an important modulator of cancer cell sensitivity to anticancer chemotherapeutic agents (106-108). Quercetin 3-O-glucoside and gemcitabine co-treatment was found to have an additive or synergistic anti-migratory effect on human PaCa cells, suggesting that this drug combination may reduce the risk of side-effects (111).

EGCG. As the most abundant catechin found in green tea and recognized for its potent chemopreventive properties, EGCG induces growth inhibition and apoptosis of various $\mathrm{PaCa}$ cell lines. In vivo studies have also demonstrated the inhibitory effect of green tea on tumorigenesis in nitrosamine-induced pancreatic tumors (112). EGCG inhibits angiogenesis, possibly through the inhibition of proangiogenic factors, including vascular endothelial growth factor (113). It has been found to be most effective against cancer of the gastrointestinal tract. EGCG has been shown to inhibit NF-kB activity, the MAPK pathway, activator protein-1 activity, and EGFR-mediated downstream signaling pathways. The antiproliferative effects of EGCG on PaCa cell growth in vitro are potentiated by treatment with pterostilbene (114).

Lycopene. One of the most extensively studied carotenoids in tomatoes, lycopene, possesses potent antioxidant activity due to its extended conjugated hydrocarbon chain. Lycopene is a acyclic isomer of $\beta$-carotene; it is synthesized by plants and microorganisms, not animals, and is a natural pigment. Lycopene has been shown to prevent carcinogenesis. Lycopene induces apoptosis and inhibits cell-cycle progression in various cancer cells, and its efficacy against xenograft tumors has been reported in a number of in vivo studies (115).

Propolis and caffeic acid phenethyl ester (CAPE). Propolis, a sticky hive product collected by bees from various plant sources, is known to have pharmacological activity, including anticancer, antioxidant and anti-inflammatory effects $(116,117)$. Bioactive components from propolis such as CAPE have been studied and shown to have antioxidant and anti-inflammatory properties that involve the inhibition of enzyme activities, such as the activation of xanthine oxidase, cyclo-oxygenase, and transcriptional factor NF-kB. CAPE inhibits EMT in $\mathrm{PaCa}$ and is a potent apoptosisinducing agent (118). Its antiproliferative activity may involve the induction of mitochondrial dysfunction and the activation of caspase-3/caspase-7 (119). CAPE induces apoptosis after autophagy inhibition in a caspase-dependent and a caspase-independent manner in PaCa cells (120). Coral et al. investigated the effect of CAPE on breast CSCs derived from aggressive triple-negative breast cancer cells and showed CAPE has effects on CSC self-renewal, progenitor formation, CD44 cell marker phenotype, cell cycle, and apoptosis (121). Their results strongly suggest that CSCs are induced into a less malignant state after CAPE treatment and may terminally differentiate their progeny, making them more susceptible to chemotherapy.

\section{Future Perspective and Conclusion}

In addition to providing an elegant model of carcinogenesis, the CSC concept has important clinical implications since targeted therapies that eliminate CSCs offer the potential to improve therapy, maintain remission, or lead to a complete cure. Emerging evidence shows that CSC-targeted therapies are effective in a preclinical setting, with a marked survival benefit. Although further studies are needed to strengthen these fondlings, CSCs seem a powerful target for more effective therapies in cancer. Regarding implementing all of the information generated by the preclinical studies, a practical approach to clinical translational may involve systems biology and bioinformatics approach to pinpoint signal hubs, molecular mediators and cross-roads that are 
Table I. Summary of compounds that have an effect on cancer stem cells.

\begin{tabular}{lcc}
\hline & Pathway & Reference \\
\hline Drugs & & 45 \\
Gemcitabine & JNK & 46 \\
Aspirin & NF-kB & 48,49 \\
Rapamycin/everolimus/temsirolimus/ridaforolimus & mTOR & 22 \\
$\gamma$-Secretase & NOTCH & 52,53 \\
Metformin & AMPK/mTOR & 57,58 \\
Salinomycin & NF-kB & 59,60 \\
Sorafenib & NF-kB, HH & 56 \\
WZB117 & GLUT1 & \\
& & 82,84 \\
Natural compounds & & 87 \\
Genistein & NOTCH, WNT, NF-kB & 102 \\
Curcumin & PI3K/AKT/NF-kB & 105,106 \\
Resveratrol & NF-kB, AKT, NOTCH, mTOR, STAT3, ERK & 114 \\
Quercetin & PI3K/AKT/mTOR, NF-kB, HH & \\
Epigallocatechin-3-gallate & NF-kB, MAPK, HH & \\
\hline
\end{tabular}

commom to all of the molecular signaling pathways required for CSC survival and maintaince indicated by the preclinical studies. These studies could provide a foundation for rationally designed molecularly therapies targeting CSCs. To succeed, future studies should focus on the identification of i) CSC-specific pathways that can be pharmacologically targeted, ii) CSC-specific surface markers for antibody therapy, iii) gene silencing approaches by siRNA or miRNAs, and iv) natural products that promote the differentiation of CSCs into progenitors that do not selfrenew or that differentiate only into normal tissue cells (summarized in Table I) (17). Although CSCs represent a very intriguing target for therapy, the CSC concept still leads to many unanswered questions. A major future goal is to address the question of clonal evolution, particularly a monitoring of CSCs during cancer development and after treatment. While CSCs may be an important target for therapy, it remains to be determined whether targeting them is the best way to neutralize their ability to progress, expand, and resist treatment in the host environment (122).

\section{References}

1 American Cancer Society Pancreatic Cancer overview. https://www.cancer.org/cancer/pancreatic-cancer.

2 Hajj C and Goodman K: Pancreatic cancer and SBRT: A new potential option? Reports of practical oncology and radiotherapy. Rep Pract Oncol Radiother 20(5): 377-384, 2015.

3 Pancreatic Cancer Action Network. https://www.pancan.org/wpcontent/uploads/2016/02/2016-GAA-PC-Facts.pdf.

4 Fitzgerald $\mathrm{T}$ and McCubrey J: Pancreatic cancer stem cells: Association with cell surface markers, prognosis, resistance, metastasis and treatment. Adv Biol Reg 56: 45-50, 2014.
5 Ashour A, Gurbuz N, Alpay S, Aziz A, Mansour A, Huo L and Ozpolat B: Elongation factor-2 kinase regulates TG2/b1 integrin/Src/uPAR pathway and epithelial-mesenchymal transition mediating pancreatic cancer cells invasion. J Cell Mol Med 18(11): 2235-2251, 2014.

6 Ashour A, Alpay S, Aziz A, Mansour A, Huo L and Ozpolat B: Targeting elongation factor-2 kinase (eEF-2K) induces apoptosis in human pancreatic cancer cells. Apoptosis 19(1): 241-258, 2014.

7 Hingorani SR, Wang L, Multani AS, Combs C, Deramaudt TB, Hruban RH, Rustgi AK, Chang $\mathrm{S}$ and Tuveson DA: Trp53R172H and KrasG12D cooperate to promote chromosomal instability and widely metastatic pancreatic ductal adenocarcinoma in mice. Cancer Cell 7(5): 469-483, 2005.

8 Feldmann G, Beaty R, Hruban RH and Maitra A: Molecular genetics of pancreatic intraepithelial neoplasia. J Hepatobiliary Pancreat Surg 14(3): 224-232, 2007.

9 Bardeesy N, Aguirre AJ, Chu GC, Cheng KH, Lopez LV, Hezel AF, Feng B, Brennan C, Weissleder R, Mahmood U, Hanahan D, Redston MS, Chin L and Depinho RA: Both p16(Ink4a) and the p19(Arf)-p53 pathway constrain progression of pancreatic adenocarcinoma in the mouse. Proc Natl Acad Sci 103(15): 5947-5952, 2006.

10 Hezel AF, Kimmelman AC, Stanger BZ, Bardesssy N and Depinho RA: Genetics and biology of pancreatic ductal adenocarcinoma. Genes Dev 20(10): 1218-1249, 2006.

11 Wood LD: Pancreatic cancer genomes: toward molecular subtyping and novel approaches to diagnosis and therapy. Mol Diagn Ther 17(5): 287-297, 2013.

12 Gnoni A, Licchetta A, Scarpa A, Azzariti A, Brunetti AE, Simone G, Nardulli P, Santini D, Aieta M, Delcuratolo S and Silvertes N: Carcinogenesis of pancreatic adenocarcinoma: precursor lesions. Int J Mol Sci 14(10): 19731-19762, 2013.

13 Wolfgang CL, Herman JM, Laheru DA, Klein AP and Erdek MA, Fishman EK and Hruban RH: Recent progress in pancreatic cancer. CA Cancer J Clin 63(5): 318-348, 2013. 
14 Qiu H, Fang X, Luo Q and Ouyang G: Cancer stem cells: a potential target for cancer therapy. Cell Mol Life Sci 72(18): 1920-1924, 2015.

15 Passegué E, Jamieson CH, Ailles LE and Weissman IL: Normal and leukemic hematopoiesis: Are leukemias a stem cell disorder or a reacquisition of stem cell characteristics? Proc Natl Acad Sci 100: 11842-11849, 2003.

16 Spangrude GJ, Heimfeld S and Weissman IL: Purification and characterization of mouse hematopoietic stem cells. Science 241(4861): 58-62, 2013.

17 Tan BT, Park CY, Ailles LE and Weissman I: The cancer stem cell hypothesis: a work in progress. Lab Invest 86(12): 12031207, 2006.

18 Bao Q, Zhao Y, Renner A, Niess H, Seeliger H, Jauch KW and Bruns C: Cancer Stem Cells in Pancreatic Cancer. Cancers 2(3): 1629-1641, 2010.

19 Rao C and Mohammed A: New insights into pancreatic cancer stem cells. World J Stem Cell 7(3): 547-555, 2015.

20 Walter D, Satheesha S, Albrecht P, Bornhauser BC, D'Alessandro V, Oesch SM, Rehrauer H, Leuschner I, Koscielniak E, Gengler C, Moch H, Bernasconi M, Niggli FK and Schafer BW: CD133-positive embryonal rhabdomyosarcoma stem-like cell population is enriched in rhabdospheres. PLoS ONE 6(5): e19506, 2011.

21 Zheng H, Ying H, Yan H, Kimmelman AC, Hiller DJ, Chen AJ, Perry SR, Tonon G, Chu GC, Ding Z, Stommel JM, Dunn KL, Wiedemeyer R, You MJ, Brennan C, Wang YA, Ligon KL, Wong WH, Chin L and DePinho RA: p53 and PTEN control neural and glioma stem/progenitor cell renewal and differentiation. Nature 455(7216): 1129-1133, 2008.

22 Wang HC, Hou YC and Shan YS: Advances in pancreatic cancer stem cells, tumor-associated macrophages, and their interplay. Cancer Cell Microenv 1: e304, 2014.

23 Gros P, Ben Neriah YB, Croop JM and Housman DE: Isolation and expression of a complementary DNA that confers multidrug resistance. Nature 323(6090): 728-731, 1986.

24 Donnenberg VS and Donnenberg AD: Multiple drug resistance in cancer revisited: the cancer stem cell hypothesis. J Clin Pharmacol 45(8): 872-877, 2005

25 Yang $\mathrm{T}$ and Rycaj K: Targeted therapy against cancer stem cells. Oncol Lett 10(1): 27-33, 2015.

26 Bao B, Ahmad A, Azmi S, Ali S and Sarkar F: Cancer Stem Cells (CSCs) and mechanisms of their regulation: implications for cancer therapy. Curr Protoc Pharmacol 14: 14-25, 2013.

27 Hermann PC, Huber SL, Herrler T, Aicher A, Ellwart JW and Guba M: Distinct populations of cancer stem cells determine tumor growth and metastatic activity in human pancreatic cancer. Cell Stem Cell 1: 313-323, 2007.

28 Hong SP, Wen J, Bang S, Park S and Song SY: CD44-positive cells are responsible for gemcitabine resistance in pancreatic cancer cells. Int J. Cancer 25: 2323-2331, 2009.

29 Mizuma M, Rasheed ZA, Yabuuchi S, Omura N, Campbell NR, de Wilde RF, De Oliveira E, Zhang Q, Puig O, Matsui W, Hidalgo M, Maitra A and Rajeshkumar NV: The gamma secretase inhibitor MRK-003 attenuates pancreatic cancer growth in preclinical models. Mol Cancer Ther 1(9): 1999-2009, 2012.

30 Abel EV, Kim EJ, Wu J, Hynes M, Bednar F, Proctor E, Wang L, Dziubinski ML and Simeone DM: The NOTCH pathway is important in maintaining the cancer stem cell population in pancreatic cancer. PLOS One 9(3): e91983, 2014.
31 Lei J, Ma J, Ma Q, Li X, Liu H, Xu Q, Duan W, Sun Q, Xu J, $\mathrm{Wu} \mathrm{Z}$ and $\mathrm{Wu} \mathrm{E}$ : Hedgehog signaling regulates hypoxia induced epithelial to mesenchymal transition and invasion in pancreatic cancer cells via a ligand-independent manner. Mol Cancer 2(66): 1476-4598, 2013.

32 Wang Y and Zhou BP: Epithelial-mesenchymal transition in breast cancer progression and metastasis. Chin J Cancer 30(9): 603-611, 2011.

33 Cui J, Jiang W, Wang S, Wang L and Xie K: Role of Wnt/ $\beta$ catenin signaling in drug resistance of pancreatic cancer. Curr Pharm Des 18(17): 2464-2471, 2012.

34 Shigeta J, Katayama K, Mitsuhashi J, Noguchi K and Sugimoto $\mathrm{Y}$ : BCRP/ABCG2 confers anticancer drug resistance without covalent dimerization. Cancer Sci 101(8): 1813-1821, 2010.

35 Dean M: ABC Transporters, drug resistance, and cancer stem cells. J Mammary Gland Biol Neoplasia 14(1): 3-9, 2009.

36 Vinogradov $\mathrm{S}$ and Wei $\mathrm{X}$ : Cancer stem cells and drug resistance: the potential of nanomedicine. Nanomedicine 7(4): 1-18, 2012.

37 Skrypek N, Vasseur R, Vincent A, Duchêne B, Seuningen I and Jonckheere $\mathrm{N}$ : The oncogenic receptor ErbB2 modulates gemcitabine and irinotecan/SN-38 chemoresistance of human pancreatic cancer cells via hCNT1 transporter and multidrugresistance associated protein MRP-2. Oncotarget 16(3): 1085310867, 2015.

38 Pang L, Word B, Xu J, Wang H, Hammons G, Huang S and Cook B: ATP-Binding cassette genes genotype and expression: a potential association with pancreatic cancer development and chemoresistance. Gastroenterol Res Pract 2014: 414931, 2014.

39 Bae YH and Park K: Targeted drug delivery to tumors: myth, reality and possibility. J Control Release 53(3): 198-205, 2011.

40 Yang C, Jin K, Tong Y and Chi Cho W: Therapeutic potential of cancer stem cells. Med Oncol 32:(6): 619, 2015.

41 Luo G, Long J, Cui X, Xiao Z, Liu Z, Shi S, Liu L, Liu C, Xu $\mathrm{J}$, Li M and Yu X: Highly lymphatic metastatic pancreatic cancer cells possess stem cell-like properties. Int J Oncol 2(3): 979-984, 2013.

42 Li C, Heidt DG, Dalerba P, Burant CF, Zhang L, Adsay V, Wicha M, Clarke MF and Simeone DM: Identification of pancreatic cancer stem cells. Cancer Res 7(3): 1030-1037, 2007.

43 Abel EV and Simeone DM: Biology and clinical applications of pancreatic cancer stem cells. Gastroenterology 44(6): 1241$1248,2013$.

44 Yang M, Wang HC, Hou YC, Tung HL, Chiu TJ and Shan YS: Blockade of autophagy reduces pancreatic cancer stem cell activity and potentiates the tumoricidal effect of gemcitabine. Mol Cancer 4: 179, 2015.

45 Suzuki S, Okada M, Shibuya K, Seino M, Sato A, Takeda H, Seino S, Yoshioka T and Kitanaka C: JNK suppression of chemotherapeutic agents-induced ROS confers chemoresistance on pancreatic cancer stem cells. Oncotarget 6(1): 458-470, 2014.

46 Zhang Y, Liu L, Fan P, Bauer N, Gladkich J, Ryschich E, Hinz U, Fortunato F and Herr I: Aspirin counteracts cancer stem cell features, desmoplasia and gemcitabine resistance in pancreatic cancer. Oncotarget 6(12): 9999-10015, 2015.

47 Karthik GM, Ma R, Lövrot J, Kis LL, Lindh C, Blomquist L, Fredriksson I, Bergh $\mathrm{J}$ and Hartman J: mTOR inhibitors counteract tamoxifen-induced activation of breast cancer stem cells. Cancer Lett 67(1): 76-87, 2015. 
48 Zeng JY, Sharma S, Zhou YQ, Yao HP, Hu X, Zhang R and Wang MH: Synergistic activities of MET/RON inhibitor BMS777607 and mTOR inhibitor AZD8055 to polyploid cells derived from pancreatic cancer and cancer stem cells. Mol Cancer Ther 13(1): 37-48, 2014.

49 Matsubara S: mTOR plays critical roles in pancreatic cancer stem cells through specific and stemness-related functions. Sci 3: 3230, 2013.

50 Francipane MG and Lagasse E: Therapeutic potential of mTOR inhibitors for targeting cancer stem cells. Br J Clin Pharmacol 2(5): 1180-1188, 2015.

51 Mueller MT, Hermann PC, Witthauer J, Rubio-Viqueira B, Leicht SF, Huber S, Ellwart JW, Mustafa M, Bartenstein P, D'Haese JG, Schoenberg MH, Berger F, Jauch KW, Hidalgo M and Heeschen C: Combined targeted treatment to eliminate tumorigenic cancer stem cells in human pancreatic cancer. Gastroenterology 37(3): 1102-1113, 2009.

52 Melnik BC and Schmitz G: Metformin: An inhibitor of mTORC1 signaling. J Endocrinol Diabetes Obes 2(2): 1029, 2014.

53 Mohammed A, Janakiram N, Brewer M, Ritchie R, Marya A, Lightfoot S, Steele V and Rao C: Antidiabetic drug metformin prevents progresion of pancreatic cancer by targeting in part cancer stem cells and mTOR signaling. Translat Oncol 6(6): 649-659, 2013.

54 Chun SG, Zhou W and Yee NS: Combined targeting of histone deacetylases and Hedgehog signaling enhances cytotoxicity in pancreatic cancer. Cancer Biol 8(14): 1328-1339, 2009.

55 Bao B, Azmi A, Ali S, Zaiem F and Sarkar F: Metformin may function as anti-cancer agent via targeting cancer stem cells: the potential biological significance of tumorassociated miRNAs in breast and pancreatic cancers. Ann Transl Med 2(6): 59, 2014.

56 Shibuya K, Okada M, Suzuki S, Seino M, Seino S, Takeda H and Kitanaka C: Targeting the facilitative glucose transporter GLUT1 inhibits the self-renewal and tumor-initiating capacity of cancer stem cells. Oncotarget 6(2): 651-661, 2014.

57 Naujokat C and Steinhart R: Salinomycin as a drug for targeting human cancer stem cells. J Biomed Biotechnol 2012: 950658, 2012.

58 Riccioni R, Dupuis ML and Bernabei M: The cancer stem cell selective inhibitor salinomycin is a P-glycoprotein inhibitör: Blood Cells Mol Dis 5(1): 86-92, 2010.

59 Vaz Arokia P, Ponnusamy M, Seshacharyulu P and Batra S: A concise review on the current understanding of pancreatic cancer stem cells. J Cancer Stem Cell Res $e$ : 1004, 2014.

60 Rausch V, Liu L and Kallifatidis G: Synergistic activity of sorafenib and sulforaphane abolishes pancreatic cancer stem cell characteristics. Cancer Res 70: 5004-5013, 2010.

61 Herr I and Buchler MW: Dietary constituents of broccoli and other cruciferous vegetables: implications for prevention and therapy of cancer. Cancer Treat Rev 6(5): 377-383, 2010.

62 Qin S, Deng Y, Li J and Zhang Z: A bioengineered murine model using $\mathrm{CD} 24{ }^{+} \mathrm{CD} 44+$ pancreatic cancer stem cells for chemotherapy study. Biomed Mater 10(1): 015004, 2015.

63 Sai S, Wakai T, Vares G, Yamada S, Kamijo T, Kamada T and Shirai T: Combination of carbon ion beam and gemcitabine causes irreparable DNA damage and death of radioresistant pancreatic cancer stem-like cells in vitro and in vivo. Oncotarget 6(8): 5517-5535, 2015.

64 Burkhart C, Fleyshman D, Kohrn R, Commane M, Garrigan J, Toshkov I and Gurova K: Curaxin CBL0137 eradicates drug- resistant cancer stem cells and potentiates efficacy of gemcitabine in preclinical models of pancreatic cancer. Oncotarget 5(22): 11038-11053, 2014.

65 Urtasun N, Vidal-Pla A and Mazo A: Human pancreatic cancer stem cells are sensitive to dual inhibition of IGF-IR and ERBB receptors. BMC Cancer 15: 223, 2015.

66 Xue Z-X, Zheng J-H, Zheng Z-Q, Cai J-L, Ye X-H, Wang C, Sun W-J, Zhou X, Lu M-D, Li P-H and Cai Z-Z: Latexin inhibits the proliferation of $\mathrm{CD}_{133}{ }^{+}$miapaca-2 pancreatic cancer stem-like cells. World J Surg Oncol 12: 404, 2014.

67 Halkova T, Cuperkova R, Minarik M and Benesova L: MicroRNAs in pancreatic cancer: involvement in carcinogenesis and potential use for diagnosis and prognosis. Gastroenterol Res Pract 2015: 892903, 2015.

68 Ma C, Huang T, Ding YC, Yu W, Wang Q, Meng B and Luo SX: microRNA-200c overexpression inhibits chemoresistance, invasion and colony formation of human pancreatic cancer stem cells. Int J Clin Exp Pathol 8(6): 6533-6539, 2015.

69 Jiang J, Li Z, Yu C, Chen M, Tian S and Sun C: MiR-1181 inhibits stem cell-like phenotypes and suppresses SOX2 and STAT3 in human pancreatic cancer. Cancer Lett 356(2 Pt B): 962-970, 2015.

70 Zhao Y, Zhao L, Ischenko I, Bao Q, Schwarz B, Bruns C and Camaj P: Antisense inhibition of microRNA-21 and microRNA-221 in tumor-initiating stem-like cells modulates tumorigenesis, metastasis, and chemotherapy resistance in pancreatic cancer. Targ Oncol 10(4): 535-548, 2015.

71 Cioffi M, Trabulo SM, Sanchez-Ripoll Y, Miranda-Lorenzo I, Lonardo E, Dorado J, Reis Vieira C, Ramirez JC, Hidalgo M, Aicher A, Hahn S, Sainz B Jr. and Heeschen C: The miR-1792 cluster counteracts quiescence and chemoresistance in a distinct subpopulation of pancreatic cancer stem cells. Pancreas 4(12): 1936-1948, 2015.

72 Shao Y, Zhang L, Cui L, Lou W, Wang D and Lu W: LIN28B suppresses microRNA let-7b expression to promote $\mathrm{CD}_{4} 4^{+} /$ LIN28B ${ }^{+}$human pancreatic cancer stem cell proliferation and invasion. Am J Cancer Res 5(9): 2643-2659, 2015.

73 Hasegawa S, Eguchi H, Nagano H, Konno M, Tomimaru Y, Wada H, Hama N, Kawamoto K, Kobayashi S, Nishida N, Koseki J, Nishimura T, Gotoh N, Ohno S, Yabuta N, Nojima H, Mori M, Doki Y and Ishii H: MicroRNA-1246 expression associated with CCNG2-mediated chemoresistance and stemness in pancreatic cancer. Br J Cancer 11(8): 1572-1580, 2014.

74 Gao L, Yang Y, Xu H, Liu R, Li D, Hong H, Qin M and Wang Y: miR-335 functions as a tumor suppressor in pancreatic cancer by targeting OCT4. Tumor Biol 5(8): 8309-8318, 2014.

75 Karlitepe A, Ozalp O and Avci CB: New approaches for cancer immunotherapy. Tumor Biol 36(6): 4075-4078, 2015.

76 Zhu Y, Karakhanova S, Huang X, Deng S, Werner J and Bazhin A: Influence of interferon- $\alpha$ on the expression of the cancer stem cell markers in pancreatic carcinoma cells. Science Direct 324(2): 146-156, 2014.

77 Umebayashi M, Kiyota A, Koya N, Katano M and Morisaki T: An epithelial cell adhesion molecule- and CD3-bispecific antibody plus activated T-cells can eradicate chemoresistant cancer stem-like pancreatic carcinoma cells in vitro. Anticancer Res 34(8): 4509-4520, 2014.

78 Lin M, Yuan YY, Liu SP, Shi JJ, Long XA, Niu LZ, Chen JB, Li Q and Xu KC: Prospective study of the safety and efficacy of a pancreatic cancer stem cell vaccine. J Cancer Res Clin Oncol 41(10): 1827-1833, 2014. 
79 Yin T, Shi P, Gou S, Shen Q and Wang C: Dendritic cells loaded with pancreatic cancer stem cells (CSCs) lysates induce antitumor immune killing effect in vitro. Plos One 9(12): e114581, 2014.

80 Li Y, Wicha M, Schwartz S and Sun D: Implications of cancer stem cell theory for cancer chemoprevention by natural dietary compounds. J Nutr Biochem 22(9): 799-806, 2011.

81 Suzuki R, Kang Y, Li X, Roife D, Zhang R and Fleming J: Genistein potentiates the antitumor effect of 5 -fluorouracil by inducing apoptosis and autophagy in human pancreatic cancer cells. Anticancer Res 34(9): 4685-4692, 2014.

82 Ma J, Cheng L, Liu H, Sarkar F, Xia J and Wang Z: Genistein down-regulates mir-223 expression in pancreatic cancer cells. Current Drug Targets 14(10): 1150-1156, 2013.

83 El-Rayes B and Ali S, Ali I, Philip P, Abbruzzese J and Sarkar F: Potentiation of the effect of erlotinib by genistein in pancreatic cancer: The Role of AKT and nuclear factor- $\mathrm{kB}$. Cancer Res 66(21): 10553-10559, 2006.

84 Banerjee S, Zhang Y, Ali S, Bhuiyan M, Wang Z, Chiao PJ, Philip PA, Abbruzzese J and Sarkar FH: Molecular evidence for increased antitumor activity of gemcitabine by genistein in vitro and in vivo using an orthotopic model of pancreatic cancer. Cancer Res 5: 9064-9072, 2005.

85 Han L, Zhang HW and Zhou WP, Chen GM and Guo KJ: The effects of genistein on transforming growth factor- $\beta 1$-induced invasion and metastasis in human pancreatic cancer cell line Panc-1 in vitro. Chin Med 125(11): 2032-2040, 2012.

86 El-Rayes B and Philip P, Sarkar F, Shields A, Wolff R and Abbruzzese J: A phase II study of isoflavones, erlotinib, and gemcitabine in advanced pancreatic cancer. Invest New Drugs 29(4): 694-699, 2011.

87 Bimonte S, Barbieri A, Palma G, Luciano A, Rea D and Arra C: Curcumin inhibits tumor growth and angiogenesis in an orthotopic mouse model of human pancreatic cancer. BioMed Res Intl 2013: 810423, 2013.

88 Ma J, Fang B, Zeng F, Pang H, Ma C, Xia J and Wang Z: Curcumin inhibits cell growth and invasion through upregulation of $m i R-7$ in pancreatic cancer cells. Toxicol Lett 31(1): 82-91, 2014.

89 Osterman CJ, Lynch J, Leaf P, Gonda A, Ferguson Bennit HR, Griffiths D and Wall NR: Curcumin modulates pancreatic adenocarcinoma cell-derived exosomal function. Plos One 10(7): e0132845, 2015.

90 Tsai C, Hsieh T, Lee J, Hsu C, Chiu C, Tsai E and Kuo P: Curcumin suppresses phthalate-induced metastasis and the proportion of cancer stem cell (CSC)-like cells via the inhibition of $\mathrm{AhR} / \mathrm{ERK} / \mathrm{SK} 1$ signaling in hepatocellular carcinoma. J Agric Food Chem 63(48): 10388-10398, 2015.

91 Devassy J, Nwachukwu I and Jones PJ: Curcumin and cancer: barriers to obtaining a health claim. Nutrit Rev 73(3): 155-165, 2015.

92 Subramaniam D, Ramalingam S, Houchen C.W and Anant S: Cancer stem cells: a novel paradigm for cancer prevention and treatment. Mini Rev Med Chem 10(5): 359-371, 2010.

93 Osterman C, Gonda A, Stiff T, Moyron R and Wall N: Curcumin induces pancreatic adenocarcinoma cell death via reduction of the inhibitors of apoptosis. Pancreas 45(1): 101109, 2016.

94 Kesharwani P, Banerjee S, Padhye S, Sarkar F and Iyer A: Parenterally administrable nano-micelles of 3,4-difluorobenzyli- denecurcumin for treating pancreatic cancer. Colloids Surf B Biointerfaces 132: 138-145, 2015.

95 Goel A, Kunnumakkara AB and Aggarwal BB: Curcumin as "Curcumin": from kitchen to clinic. Biochem Pharmacol 75(4): 787-809, 2008.

96 Thangapazham RL, Sharma A and Maheshwari RK: Multiple molecular targets in cancer chemoprevention by curcumin. AAPS J E: 443(9): 443-E449, 2006.

97 Patel BB, Sengupta R, Qazi S, Vachhani H, Yu Y, Rishi AK and Majumdar AP: Curcumin enhances the effects of 5-fluorouracil and oxaliplatin in mediating growth inhibition of colon cancer cells by modulating EGFR and IGF-1R. Int J Cancer 122(2): 267-273, 2008.

98 Kakarala M, Brenner DE, Korkaya H, Cheng C, Tazi K, Ginestier C, Liu S, Dontu G and Wicha MS: Targeting breast stem cells with the cancer preventive compounds curcumin and piperine. Breast Cancer Res Treat 112(3): 777-785, 2009.

99 Liu P, Liang H, Xia Q, Li P, Kong H, Lei P, Wang S and Tu Z: Resveratrol induces apoptosis of pancreatic cancer cells by inhibiting miR-21 regulation of BCL-2 expression. Clin Transl Oncol 15(9): 741-746, 2013.

100 Xu Q, Zong L, Chen X, Jiang Z, Nan L, Li J, Duan W, Lei J, Zhang L, Ma J, Li X, Wang Z, Wu Z, Ma Q and Ma Z: Resveratrol in the treatment of pancreatic cancer. Ann NY Acad Sci 348(1): 10-19, 2015.

101 Qin Y, Ma Z, Dang X, Li W and Ma Q: Effect of resveratrol on proliferation and apoptosis of human pancreatic cancer MIA $\mathrm{PaCa}-2$ cells may involve inhibition of the Hedgehog signaling pathway. Mol Med Rep 10(5): 2563-2567, 2014.

102 Li W, Ma J, Ma Q, Li B, Han L, Liu J, Xu Q, Duan W, Yu S, Wang $\mathrm{F}$ and $\mathrm{Wu}$ E: Resveratrol inhibits the epithelialmesenchymal transition of pancreatic cancer cells via suppression of the PI-3K/Akt/NF-kB pathway. Curr Med Chem 20(33): 4185-4194, 2013.

103 Appari M, Babu K, Gross W and Herr I: Sulforaphane, quercetin and catechins complement each other in elimination of advanced pancreatic cancer by miR-let- 7 induction and Kras inhibition. Int J Oncol 45(4): 1391-1400, 2014.

104 Angst E, Park JL, Moro A, Lu QY, Lu X, Li G, King J, Chen M, Reber HA, Go VL, Eibl G and Hines OJ: The flavonoid quercetin inhibits pancreatic cancer growth in vitro and in vivo. Pancreas 2(2): 223-229, 2013.

105 Zhou W, Kallifatidis G, Baumann B, Rausch V, Mattern J, Gladkich J, Giese N, Moldenhauer G, Wirth T, Büchler MW, Salnikov AV and Herr I: Dietary polyphenol quercetin targets pancreatic cancer stem cell. Int J Oncol 37(3): 551$561,2010$.

106 Jung JH, Lee JO, Kim JH, Lee SK, You GY, Park SH, Park JM, Kim EK, Suh PG, An JK and Kim HS: Quercetin suppresses HeLa cell viability via AMPK-induced HSP70 and EGFR down-regulation. J Cell Physiol 23(2): 408-414, 2010.

107 Nishiumi S, Miyamoto S, Kawabata K, Ohnishi K, Mukai R, Murakami A, Ashida $\mathrm{H}$ and Terao J: Dietary flavonoids as cancer-preventive and therapeutic biofactors. Front Biosci 3: 1332-1362, 2011.

108 Cao C, Sun L, Mo W, Luo J, Yang Z and Ran Y: Quercetin mediates $\beta$-catenin in pancreatic cancer stem-like cells. Pancreas 44(8): 1334-1339, 2015.

109 Chen C, Zhou J and Ji C: Quercetin: A potential drug to reverse multidrug resistance. Life Sci 11(87): 333-338, 2010. 
110 Limptrakul P, Khantamat O and Pintha K: Inhibition of Pglycoprotein function and expression by kaempferol and quercetin. J Chemoter 17(1): 86-95, 2005.

111 Lee J, Han S, Yun J and Kim J: Quercetin 3-O-glucoside suppresses epidermal growth factor-induced migration by inhibiting EGFR signaling in pancreatic cancer cells. Tumor Biol 36(12): 9385-9393, 2015.

$112 \mathrm{Lu} \mathrm{Qi}$, Zhang L, Yee J, Go VL and Lee W: Metabolic Consequences of LDHA inhibition by epigallocatechin gallate and oxamate in MIA PaCa-2 pancreatic cancer cells. Metabolomics 11(1): 71-80, 2015.

113 Bimonte S, Leongito M, Barbieri A, Vecchio V, Barbieri M, Albino V, Piccirillo M, Amore A, Di Giacomo R, Nasto A, Granata V, Petrillo A, Arra C and Izzo F: Inhibitory effect of (-)-epigallocatechin-3-gallate and bleomycin on human pancreatic cancer Mia Paca-2 cell growth. Infect Agents Cancer 10: 22, 2015.

114 Kostin S, McDonald D and McFadden D: Inhibitory effects of epigallocatechin-3-gallate and pterostilbene on pancreatic cancer growth in vitro. J Surg Res 77(2): 255-262, 2012.

115 Rao V and Agarwal S: Role of antioxidant lycopene in cancer and heart disease. J Am Coll Nutrit 19(5): 563-569, 2000.

116 Li F, Awale S, Tezuka Y, Esumi H and Kadota S: Study on the constituents of mexican propolis and their cytotoxic activity against PANC-1 human pancreatic cancer cells. J Nat Prod 73(4): 623-627, 2010.

117 Sawicka D, Car H, Borawska M and Nikliński J: The anticancer activity of propolis. Folia Histochem Cytobiol 50(1): 25-37, 2012.
118 Chen MJ, Shih SC, Wang HY, Lin CC, Liu CY, Wang TE, Chu $\mathrm{CH}$ and Chen YJ: Caffeic acid phenethyl ester inhibits epithelial-mesenchymal transition of human pancreatic cancer cells. Evid-Based Complement Altern Med 2013: 270906, 2013.

119 Papademetrio DL, Lompardía SL, Simunovich T, Costantino S, Mihalez CY, Cavaliere V and Álvarez É: Inhibition of survival pathways MAPK and NF-kB triggers apoptosis in pancreatic ductal adenocarcinoma cells via suppression of autophagy. Targ Oncol 1(2): 183-195, 2015.

120 Rzepecka-Stojko A, Kabała-Dzik A, Moździerz A, Kubina R, Wojtyczka RD, Stojko R, Dziedzic A, Jastrzębska-Stojko Ż, Jurzak M, Buszman E and Stojko J: Caffeic acid phenethyl ester and ethanol extract of propolis induce the complementary cytotoxic effect on triple-negative breast cancer cell lines. Molecules 20(5): 9242-9262, 2015.

121 Omene C, Wu J and Frenkel K: Caffeic acid phenethyl ester (CAPE) derived from propolis, a honeybee product, inhibits growth of breast cancer stem cells. Invest New Drugs 30(4): 1279-1288, 2011.

122 Lonardo E, Hermann P and Heeschen C: Pancreatic cancer stem cells: update and future perspectives. Mol Oncol 4(5): 431-442, 2010. 